\title{
Analysis Of Light Gauge Steel By Using Fem Subjected To
}

\section{Tension Load}

\author{
Dr.A.Paulmakesh ${ }^{\text {a }}$ Gizachew Markos Makebo $^{\text {b }}$ \\ ${ }^{a}$ Associate professor, department of civil Engineering, Wolaita Sodo University, \\ Ethiopia. E-mail: paulmakesh1986@gmail.com \\ ${ }^{\mathrm{b}}$ Head, department of civil Engineering, Wolaita Sodo University, Ethiopia, \\ E- mail: gizemark2009@gmail.com
}

\begin{abstract}
The effective sectional area concept was adopted to conduct the analysis of cold-formed Tension members. ANSYS software was utilized to simulate the behavior of cold-formed steel angle under tension load. The paper describes the results from a finite element investigation into the load capacity tension members of single angle sections of 1.5,.1.6,2 3,4 $\mathrm{mm}$ and double angles sections of $2 \mathrm{~mm}$ under plain (without Lipped) and with Lipped conditions subjected to tension. Numerical investigations were carried out using finite element software ANSYS. In order to simulate the experimental behavior using the analytical model, material non-linearity's and geometric nonlinearity's were incorporated. The ultimate strength for cross - sectional dimensions with varying eccentricity loads under tension loading conditions was achieved through the ANSYS 15.0 workbench. In the numerical investigation, 180 specimens were modeled on tensioning elements attached to bolts. To find equivalent stress, equivalent elastic strain and total deformation of singleand double-angle sections were investigated.
\end{abstract}

\section{INTRODUCTION}

The Finite element method is a handy tool of analysis in many fields of Engineering. The finite element method is an accurate and flexible technique to forecast the performance of a structure, mechanism, or process under different loading conditions. The structural behavior observed during the tests was used for develop a FEM, particularly during the non-linear analysis. In angles under tension, the behaviour is non-linear as the failure approaches. Static analysis are conducted as Finite Element Analysis (FEA) using ANSYS Workbench. The static structural component and all of its modules is created. The modules are similar to those in ANSYS MAPDL (Mechanical Ansys Parametric Design Language). The static analysis of FEA are build geometry, define materials, generate mesh, apply load, solving the model and reviewing the results. Models have been developed to calculate the structural investigations of single and double sections from linear through non linear response and upto failure. Modeling simplifications and assumptions developed during this research are presented. The study compared the ultimate load carrying capacity of the single and double angle section from the Finite Element Analysis (FEA) with measured failure load.

FEM of cold formed structures plays an increasingly important role in engineering problems, as it is relatively in expensive and time efficient compared to physical experiments. Especially when involving a parametric study of cross- section geometries. FEA is an efficient analytical tool that can accurately predict the behavior as long as the developed model is similar to the experimental prototype. It is therefore necessary to verify the results of the finite elements with the experimental results. FEA is generally a powerful tool to predict the ultimate loads and complex failure modes of cold formed steel members.

\section{FINITE ELEMENT ANALYSIS}

Finite element analysis as applied in engineering is a computer tool for engineering and 3D structural solid elements analysis. It is a way of stimulating load conditions in a design and determining the response of the design to these conditions. The design is modeled using discrete building blocks is called elements. The FEM method is a numerical method for finding approximate solutions to limit value problems for partial differential equations. It is also known as an analysis of Finite Elements 
(FE). FEM divides a significant problem into smaller, simpler, called finite elements. Civil FEM is a set of ANSYS integrated pre- processing, solution and post- processing application which makes it easier for the user to deal with civil engineering issues. The aim of the Finite Element Analysis is to develop a model that can study the behavior of single and double angle bolted cold formed steel components. The behaviour observed during the tests was used for preparing a finite element model, particularly during the non linear analysis. In angles under tension, the behaviour is highly nonlinear as the failure approaches. The model of finite elements included both geometric and non linear material effects. The front edge of the guesset plate is restricted in all directions except the longitudinal direction. On the front edge of the gusset plate, a longitudinal displacement limit condition is applied. The maximum stress and strain is obtained around the bolt hole.

\subsection{ANSYS Workbench}

ANSYS (Workbench) 15.0 makes it easy to evaluate the quality of the elements during the development of meshing controls and the results of post processing. Well formed elements deliver superior results and help reduce element shape errors during large scale displacement analysis, such as when using hyperelastic materials with a significant strain. This article briefly reviews the features in the workbench outline for displaying the quality of the elements (i) in color in the mesh branch (ii) using element quality bar charts (iii) plotting the quality of the elements in post- processing after element shapes have been distorted by strain in a model. The ANSYS capabilities include unique and extensive steel structure materials and sections. The user could also add the various shapes or materials to the corresponding ANSYS library. Ansys work bench focuses on geometry creation and optimization, attaching existing geometry, setting up the finite element model, solving, and reviewing results.

\subsection{Static Structural Analysis}

A static structural analysis determines the displacements, stresses, strains and forces in structures or components caused by loads that do not induce substantial inertia and damping effects. Steady loading and response conditions are assumed that is, the loads and the structure's response are assumed to vary slowly with respect to time. A static structural load can be performed using the ANSYS workbench. A static structural analysis can be either linear or nonlinear. The ANSYS 15.0 was used to perform a static structural load. The static material properties of the tension tests and the measured cross sectional dimensions were used to model the angle specimens. This document serves as a step by step guide for conducting a Finite Element Analysis (FEA) using ANSYS Workbench. It will cover the use of the simulation package through the Graphical User Interface (GUI). A linear static analysis is an analysis where a linear relation holds between applied forces and displacements. In practice, this is applicable to structural problems where stresses remain in the linear elastic range of the used material. In a linear static analysis the model's stiffness matrix is constant, and the solving process is relatively short compared to a nonlinear analysis on the same model. A nonlinear analysis is an analysis where a nonlinear relation holds between applied forces and displacements. Nonlinear effects can originate from geometrical nonlinearity's (i.e. large deformations), material nonlinearity's (i.e. elasto-plastic material), and contact. These effects result in a stiffness matrix which is not constant during the load application.

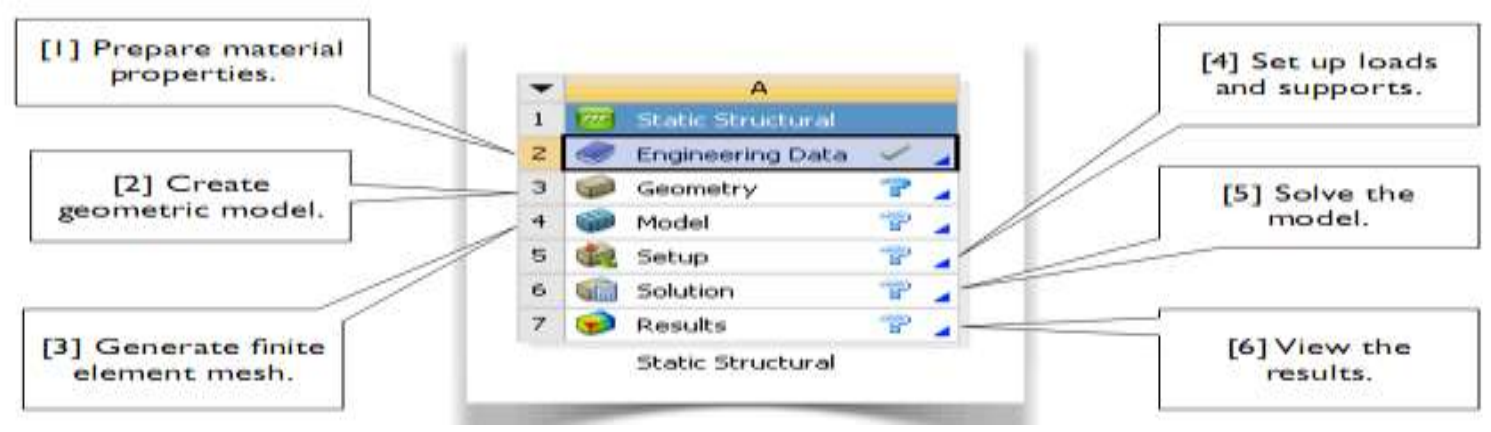

Fig .1 Static Structural Simulations 


\section{STRUCTURAL BEHAVIOR OF COLD FORMED STEEL}

The cold formed steel profiles are recently playing a major role in the civil engineering industry. The main reason is that these profiles offer many advantages compared to hot rolled sections. Products are characterized by two main properties such as the yield point and the tensile strength. Other important properties are ductility, hardness, and weldability. It increases the design flexibility and more over allows very attractive, economical and sustainable sections. The factor of safety for angles under tension in the limit state format giving due considerations to block shear failure, net section efficiency and yielding of gross section was obtained.

In order to understand the behavior of cold formed steel bolted connection tests, to determine tensile capacity, bearing capacity and the interaction of tension and bearing capacities were performed. Instead of failure through material yielding, compressed components tend to lose their stability. In the local buckling mode, flat plate fields cause displacements perpendicular to plane components and stress distribution. The shape of the section is slightly distorted during this mode as a result of only rotations of the plane part junctures are concerned. In the actual distorting buckling mode, displacement of cross section parts is mainly due to buckling e.g. flange stiffeners. The stiffness of the cross section could also be modified in each buckling modes, however the member most likely still has some post buckling capability. Since, the interpretation and or rotation of the complete cross section isn't concerned. In the global buckling mode, all cross section displacements are large, resulting in an overall loss of member stability. Global buckling modes depend mainly on cross section shape. Flexural buckling is typically common for cold formed members in the direction of minimum flexural stiffness.

\subsection{Strength}

\section{Benefits of cold formed steel}

Steel has the highest weight ratio of any building material. In addition, the strength of cold formed steel also gives architects greater flexibility, allowing designs with longer spans and other architectural features. When a steel section is cold formed from flat sheet or strip the yield strength, and to a lesser extent the ultimate strength, are increased as a result of this cold working, particularly in the bends of the section.

\subsection{Durability}

Ductility is defined as an extent to which a material can sustain plastic deformation without rupture. The steel is inorganic, impervious to termites, rust and mold.A protective layer of zinc and other metallic coating steel provides long term durability which research demonstrates can last without deterioration for hundreds of years. There is great flexibility in the design using cold formed steel.

\subsection{Stability}

Cold formed steel is highly reliable when subjected to structural loads and stresses of high wind and seismic forces. The Cold formed steel used can not absorb moisture, thus removing most of the expansion and contraction of cracks, warps and other defects in both internal and external finishes.

\subsection{Non combustibility}

Steel does not burn and does not contribute to a fire's spread or intensity. This makes it easy for cold formed steel projects to meet code's fire rating requirements. Non fuel structures such as those built with cold formed steel framing have a better history of loss than fuel wood framing. This often results in lower costs and wider coverage of many types of building insurance.

\subsection{Sustainability}

Steel is the only infinitely recyclable building material and most sustainable construction materials. As a recognized green building material, cold formed steel framing projects can earn. 


\section{LITERATURE REVIEW}

Chou and Chai (2014) presented a FEM on the post buckling behavior of thin walled CFS lipped channel and hat-section stub columns under axial compression. Numerical predictions on the load versus end-shortening characteristics and ultimate load capacity of the sections were obtained using a non-linear Analysis. Standard design procedures were developed for post-buckling analysis of thinwalled stub columns using finite element method. Results from the design procedure correlated well with the experimental results and BS: 5950 -1998 (part 5) predictions.

Chung and Ip (2018) investigated the Finite element method of bolted connections between cold formed steel strips and hot rolled steel plates under shear. The modeling was done with threedimensional solid elements using the results of the coupon tests. Twelve lap shear tests with two steel grades, one bolt diameter and two washer sizes were carried out to caliber the finite element models. The patterns of yielding, strength degradation and strain distribution of connections were established in detail using finite element analysis of ANSYS software. Typical strain levels in cold formed steel strips in the vicinity of bolt holes were found to be $40 \%$. It as served to incorporate reduced strength at larger strains for accurate prediction of the load carrying capacities of bolted connection.

Davi Fagundes Leal (2017) presented a numerical analysis based on the Finite Element Method (FEM) is proposed in order to investigate cold formed steel back-to-back double angle structural behavior under compression. Considering non-linear analysis, an investigation was performed to analyze the influence of some aspects, such as the loading condition, the boundary conditions, the global slenderness, the global and local geometric imperfections, the angle thickness and the number of packing plates. The numerical results signalize that the compression strength obtained in accordance with the standards may be quite conservative, mainly in the lower global slenderness cases. Additionally, the connection spacing and the presence of a connection at midlength change the buckling mode, as well as cause a significantly increase in the axial compression strength of the member. The numerical analysis also indicates that the design proposes for the case involving angles under compression.

Mahmood Tahir and Poi NgianShek (2014) reported the concept of cold formed light steel framing construction has been widespread after understanding its structural characteristics with massive research works over the years. Connection serves as one of the important elements for light steel framing in order to achieve its structural stability. Compared to hot roll steel sections, cold formed steel connections perform dissimilarly due to the thin-walled behaviour. Screw is a common type of connections that is used in cold-formed steel due to the thinness of the cold-formed steel sections The performance of these connections in the design of cold formed steel structures was discussed. This review is initiated to summaries researches on cold formed steel connections. The scopes of discussion as well as the length of the publication limit the work. Several other researches are worth to be further discussed. This paper summarizes previous research on cold-formed steel connections in the area of screw connection, storage rack connection, welded connection, and bolted connection.

Yerudkar and Vesmawala (2015) presented the structural applications have caused a significant growth in cold formed steel relative to the traditional heavier hot rolled steel structural members. This development has been a combination of improvements in technology and developments in applications. It has placed researchers under some demands to find adequate practical design procedures for increasingly complicated section shapes. Practical design models have been developed for the local and distortional buckling, and the interaction between them. Above review concludes that for cold formed steel columns and beams with the proportions typically used in practice, distortional buckling is often critical. Some design codes actually specify the need to use second order analysis under certain conditions. The direct strength method makes a more formal allowance for post-buckling and is evidently more appropriate when local buckling is significant. 

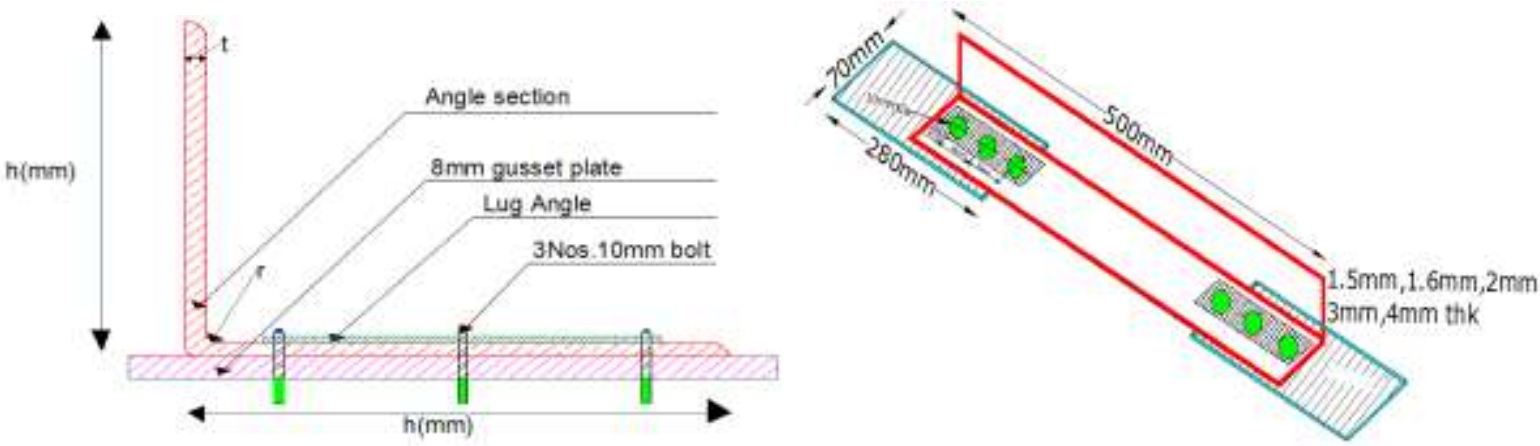

Fig 2 Details of single angles specimens without lip on connected with gusset plate
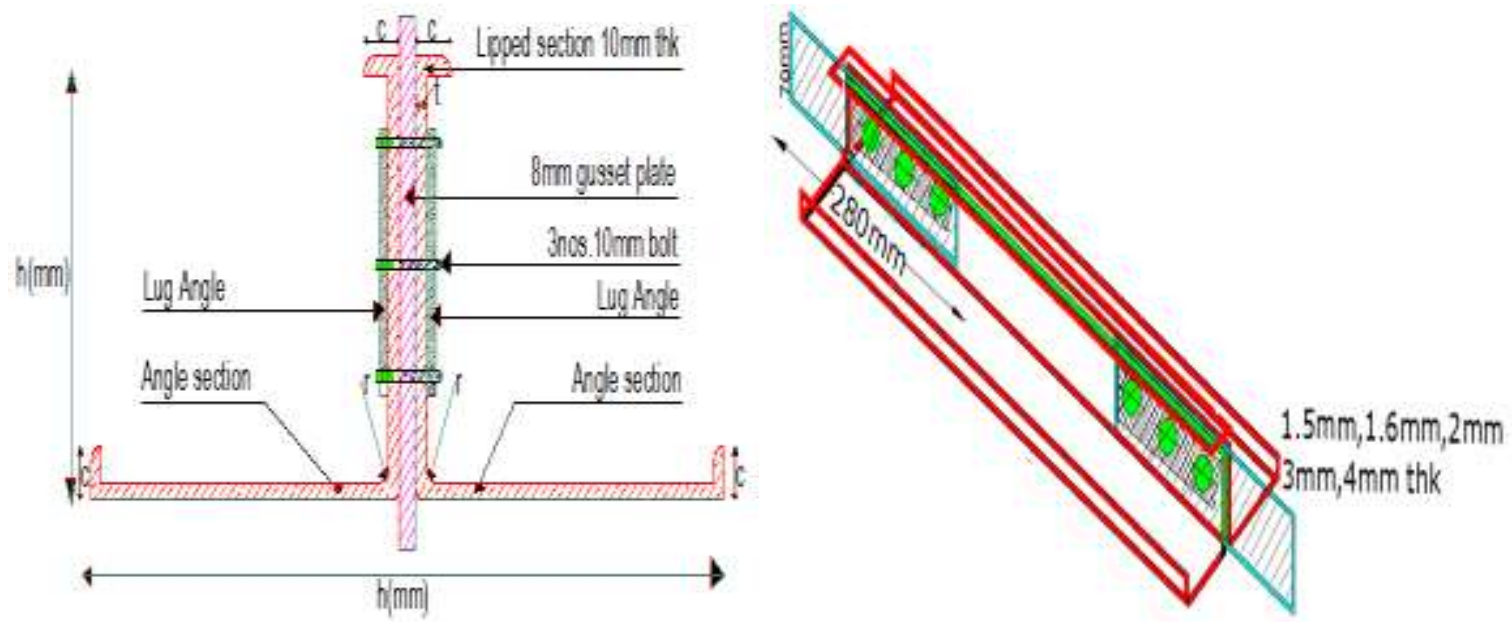

Fig 3 Details of double angles specimens with lip on connected to opposite side with gusset plate

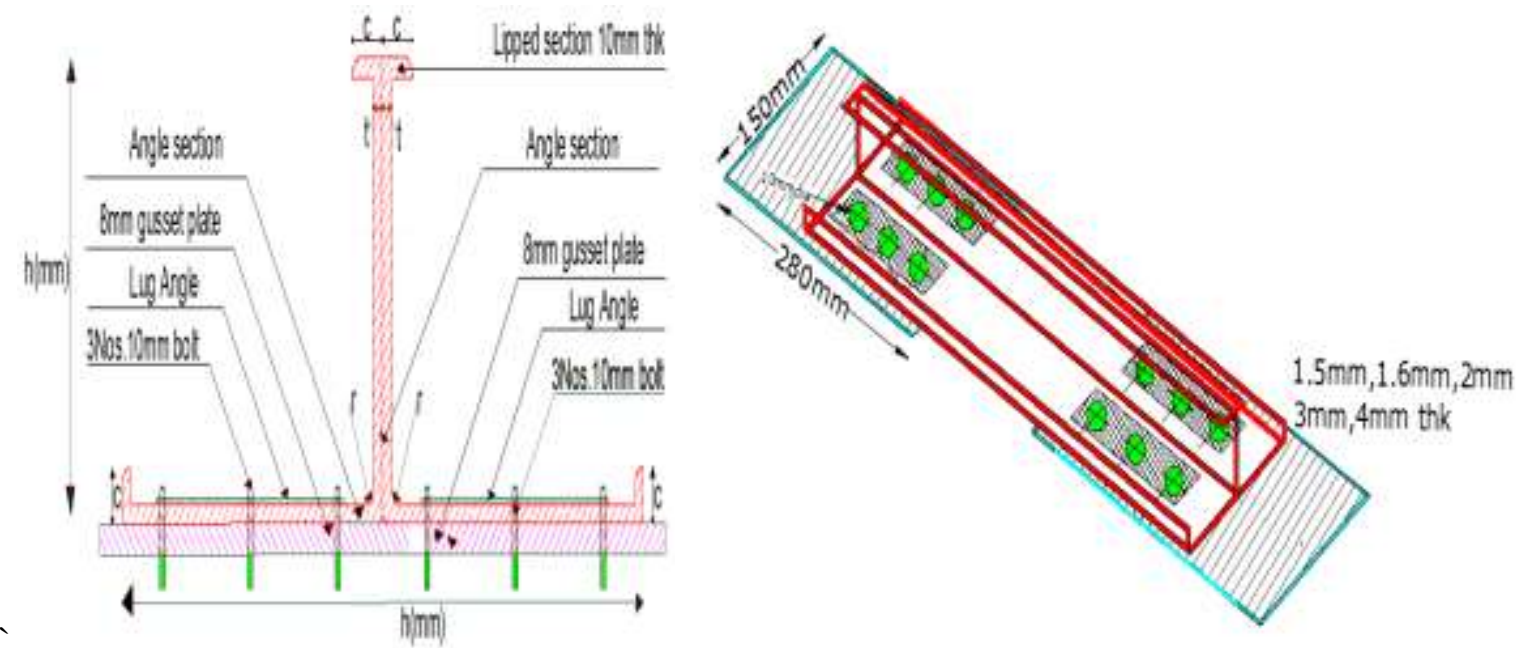

Fig 4 Details of double angles specimens with lip on connected to same side with gusset plate 


\section{Modeling of Structures}

Modeling is one of the essential aspects of the analysis of finite elements. The cold-formed steel was used to create the model to define the material. The engineering specifications of the AISI 1020 coldformed steel are given as the input of the analyzing material in the ANSYS workbench. These data inputs play an important role in the analysis of the structure's behavior during the analysis. These input data are based on both British and Indian standards. Using the model type of linear elastic isotropic, the value of Elastic modulus is $2.05 \times 10^{5} \mathrm{~N} / \mathrm{mm}^{2}$, Possion's ratio is 0.290 , shear modulus is $80 \times 10^{3} \mathrm{~N} / \mathrm{mm}^{2}$, Density of mass is $7870 \mathrm{~kg} / \mathrm{m}^{3}$, Tensile strength $\left(\mathrm{f}_{\mathrm{t}}\right)$ are $261-344 \mathrm{~N} / \mathrm{mm}^{2}$ and yield strength $\left(\mathrm{f}_{\mathrm{y}}\right)$ are $216-244 \mathrm{~N} / \mathrm{mm}^{2}$ were been used for modeling the angle sections.

In order to study the numerical investigations of single and double angle cold formed steel members under tension loading using the finite element analysis software ANSYS 15.0. The ultimate load was predicted and the shear deformation was evaluated at the cross section. 180 specimens were investigated using ANSYS of the thickness $1.5 \mathrm{~mm}, 1.6 \mathrm{~mm}, 2 \mathrm{~mm}, 3 \mathrm{~mm}$ and $4 \mathrm{~mm}$ was used. All Angle specimens were connected with their larger leg to end gusset plates of mild steel of $8 \mathrm{~mm}$ thickness using $10 \mathrm{~mm}$ bolts. All the specimens were fabricated for a length of $500 \mathrm{~mm}$. The size of gusset plates are $70 \mathrm{~mm} \times 280 \mathrm{~mm}$ for single angles specimen and double angles specimen on opposite side, similarly the size of gusset plates are $150 \mathrm{~mm}$ x $280 \mathrm{~mm}$ for double angle specimen on same side. Fig 4.2 to 4.6 shows the modeling of single angle sections and double angle sections.

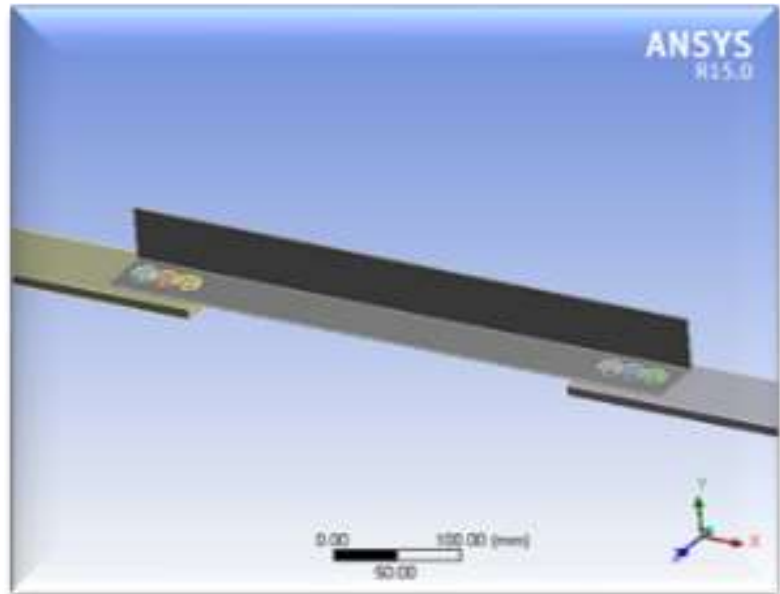

Fig 5a Single angle without lip $50 \times 50 \times 1.5$

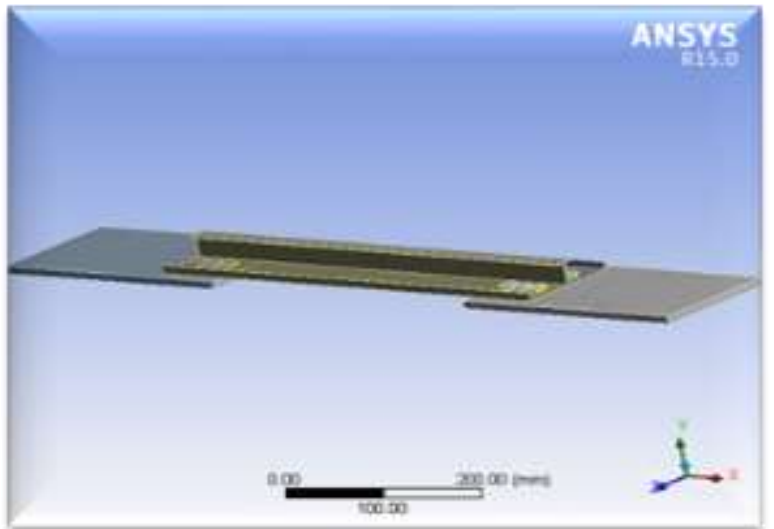

Fig 5c Double angle connected to same side with lip 70x60x30x3

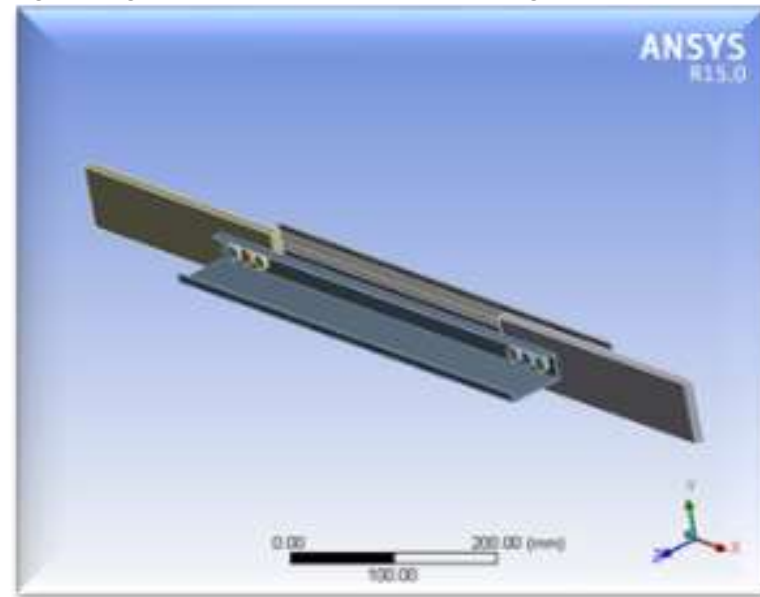

Fig $5 b$ Double angle connected to opposite side with lip 60x30x2

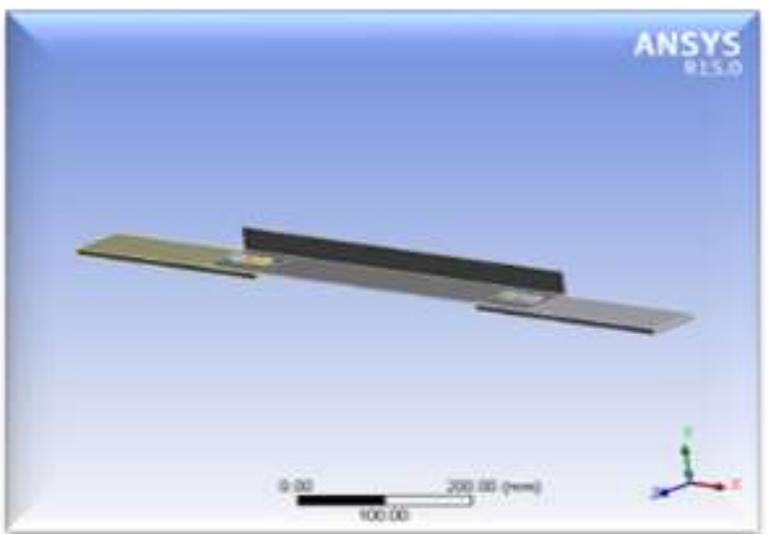

Fig 5d Single angle without lip 70x35x4 


\subsection{Element co ordinates system}

The ANSYS program contains various types of coordinate systems each of which is used for a different reason. Global and local coordinate systems are used to locate geometry in space. The display coordinate system determines the system in which the geometry elements are listed. The Nodal Coordinate System (NSC) defines the degree of freedom direction at each node and the orientation of the nodal results. ECS determines the orientation of the material properties and the results of the element data. The result coordinate system is used to transform nodal or element result data into a specific coordinate system for listing, display or general post- processing. The program provides a GCS. The Global system type is Cartesian. Each element in a model has an element coordinate system associated with it. Its purpose is to orient the following quantities of orthotropic material properties and stresses calculated during the solution.

\subsection{Element Type}

CONTRA 174, SOLID 186, SOILD 187, SURF 175 and TARGE 170 are the element varients types used to model the single angle and double angle sections. The degrees of freedom of the element determine the discipline for which the element is applicable is statics structural. The element type was chosen such that the degrees of freedom are sufficient to characterize the model's response. It has both bending and membrane capabilities. The element has plasticity, hyper elasticity, stress stiffening, creep, large deflection and large strain capabilities, incompressible elastro plastic materials and fully incompressible hyper elastic materials.

Contact and sliding between 3D target surfaces was used for CONTA 174. This element applies to structural 3D and coupling field contact analysis. The locations of the geometry and nodes are shown in Fig 4.7a. The element is defined by eight nodes. It can degenerate into six nodes depending on the shape of the solid or shell elements under lying it. There are two types of geometry for this element. Surface smoothing and bolt thread surface smoothing is a geometry correction technique that eliminates facial element in accuracies. Bolt thread modeling provides a method to simulate contact between a threaded bolt hole and a bolt hole without modeling the detailed geometry of the thread.

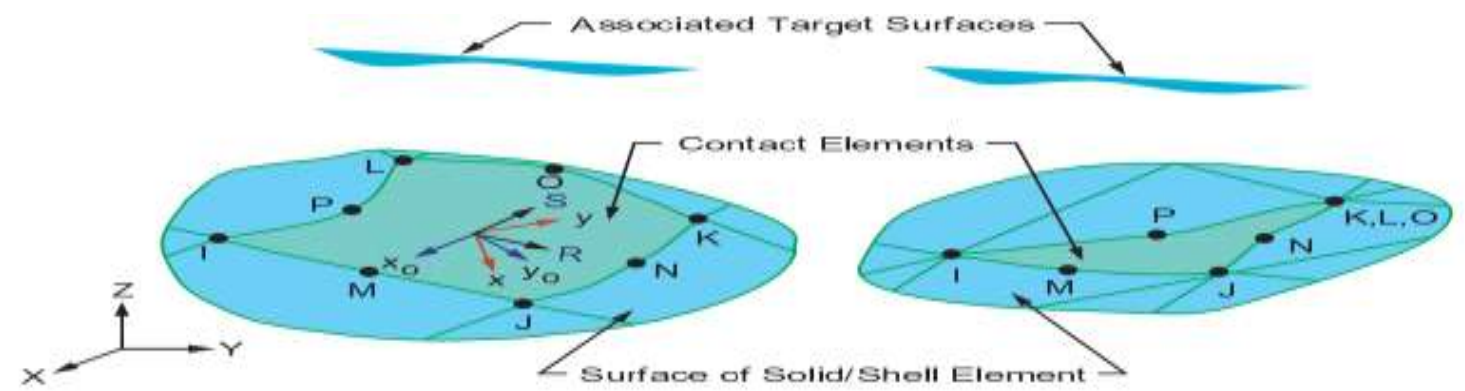

Fig 6 Element type of CONTA 174

SOLID 186 is a higher order 3D 20 node solid element with a quadratic behavior of displacement. The element is defined by 20 nodes with three degrees of freedom per node in the $\mathrm{x}, \mathrm{y}$ and $\mathrm{z}$ directions. The element supports plasticity, hyper elasticity, stress stiffening, creep, large deflection, and large strain capabilities. It also has the ability to simulate deformations of almost incompressible elasto plastic materials and completely incompressible hyper elastic materials in mixed formulation. Fig 4.7b shows the geometry, the location of the node and the element coordinate system. SOLID 186 homogeneous structural solid is suitable for irregular mesh modeling. 

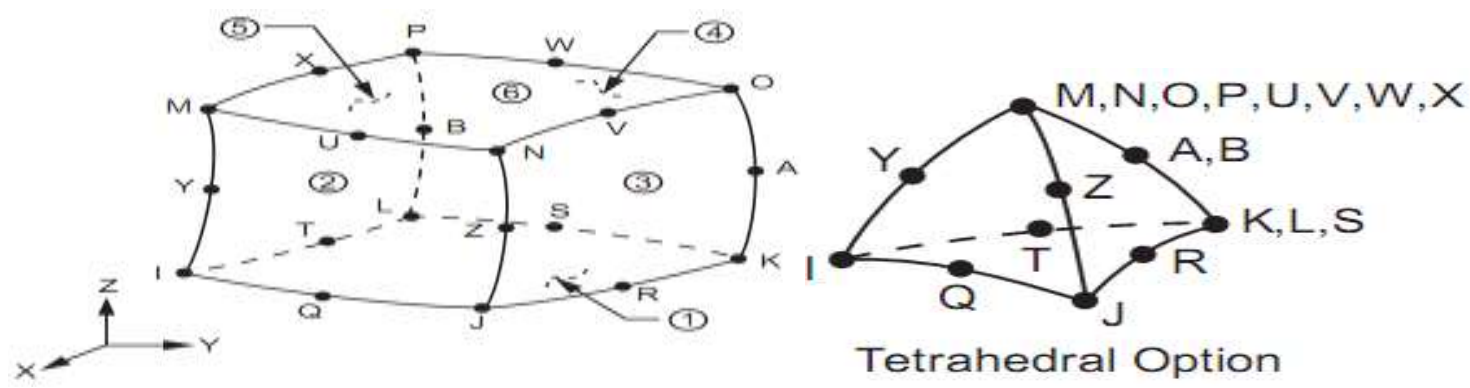

Fig 7 Element type of SOLID 186

The SOLID 187 element is a 3D, 10 node element in higher order. SOLID 187 quadratic displacement behavior and is suitable for irregular mesh modelling.

has a defined by 10 nodes with three degrees of freedom per node in the $\mathrm{x}, \mathrm{y}$ and $\mathrm{z}$ directions. The element has plasticity, hyper elasticity, creep, tension stiffening, high deflection and large strain capabilities. It also has the ability to simulate deformations of almost incompressible elasto plastic materials and completely incompressible hyper elastic materials in mixed formulation. The locations of the geometry and nodes are shown in Fig 4.7c.
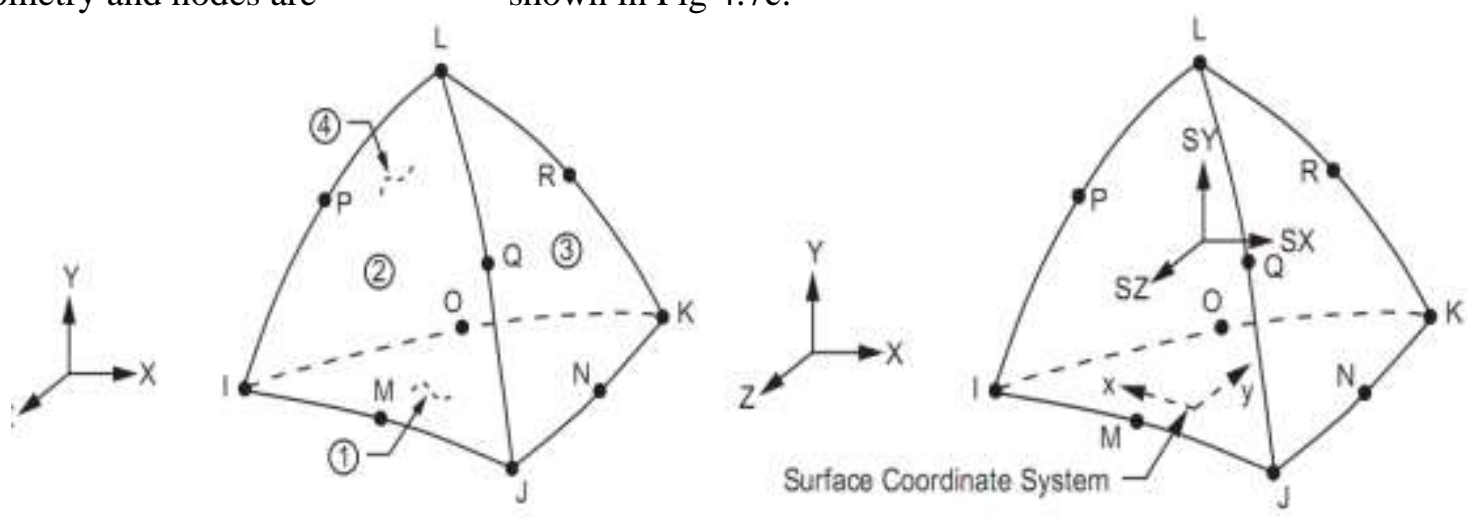

Fig 8 Element type of SOLID 187

SURF 175 described the geometry, node locations and the coordinate system are shown in Fig 4.7d. The elements are defined by four to eight nodes and the material properties. A triangular element may be formed by defining duplicate $\mathrm{K}$ and $\mathrm{L}$ node numbers as described in degenerated shape elements. The default element $\mathrm{X}$ - axis is parallel to the I- $\mathbf{J}$ side of the element. The surface tension load vector acts in the element's plane as a constant force applied to the nodes, which seeks to minimize the surface area.

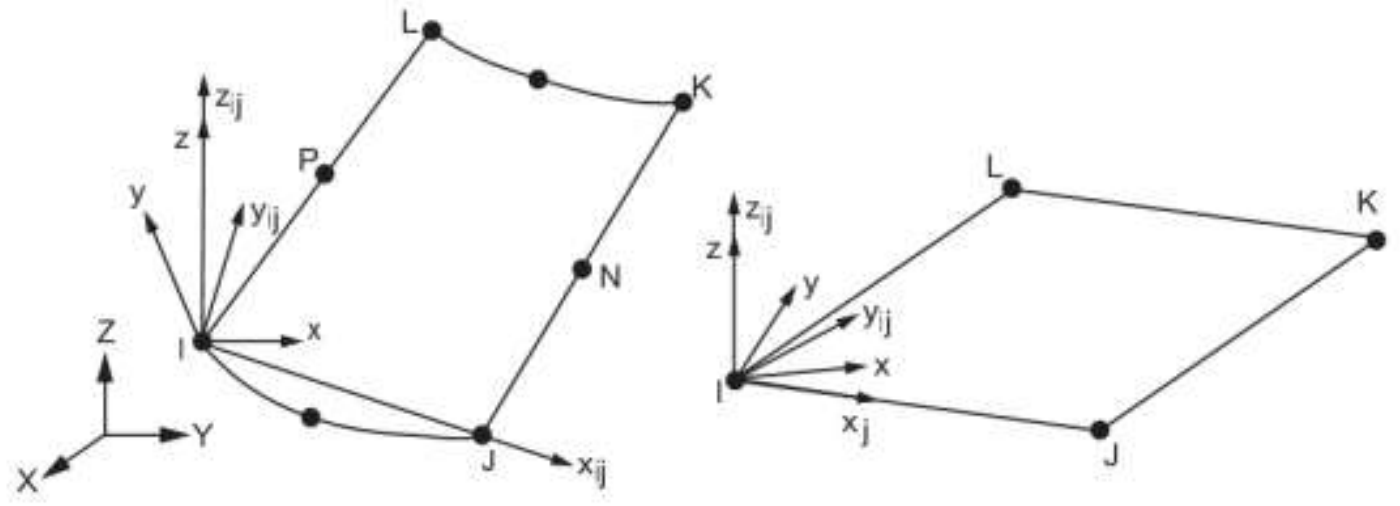

Fig 9 Element type of SURF 175

TARGE 170 is used to represent various 3D target surfaces for the associated contact elements. The contact elements themselves over lay the soild, shell or line elements describing the boundary of a deformable body and are potentially in contact with the target surface. Fig 4.7 e shows the available segment types for TARGE 170. The general 3D surface segments 3 node and 6 node triangles, and 4 
node and 8 node quadrilaterals.

Each target segment of a rigid surface is a single element with a specific shape or segment type. The segment types are defined by several nodes and a target shape . Fig 4.6 shows the element type of TARGE 170.

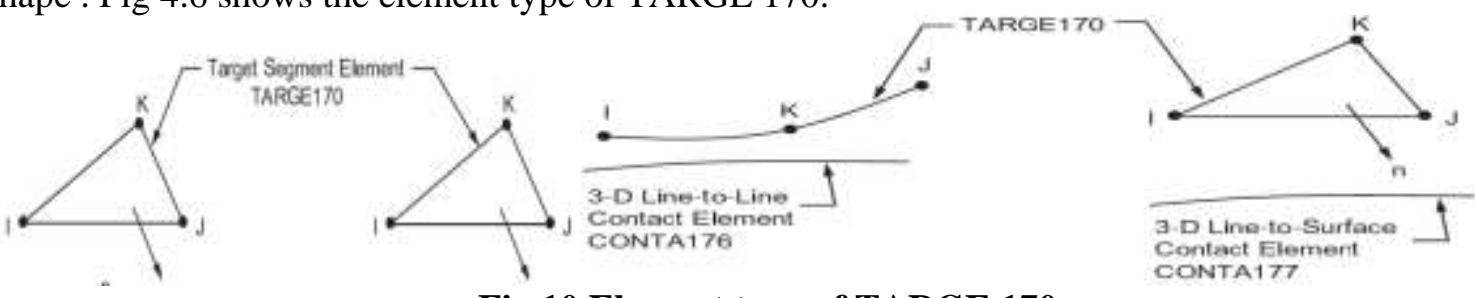

Fig 10 Element type of TARGE 170

\subsection{Loading and boundary conditions}

The finite element model is created with the software ANSYS workbench 15. Types of elements are used for meshing the specimens geometry. For all specimens, the boundary conditions were chosen to simulate the actual experimental setting. The length of specimens are $500 \mathrm{~mm}$. The bolted end conditions were considered as fixed support. The length of gusset plate was provided according to the requirement of pitch and edge distance as per Indian code of practice. The pitch and end distance is held as $30 \mathrm{~mm}$ and $20 \mathrm{~mm}$ respectively. Single angle sections members and double angle sections members was modeled by using ANSYS workbench.

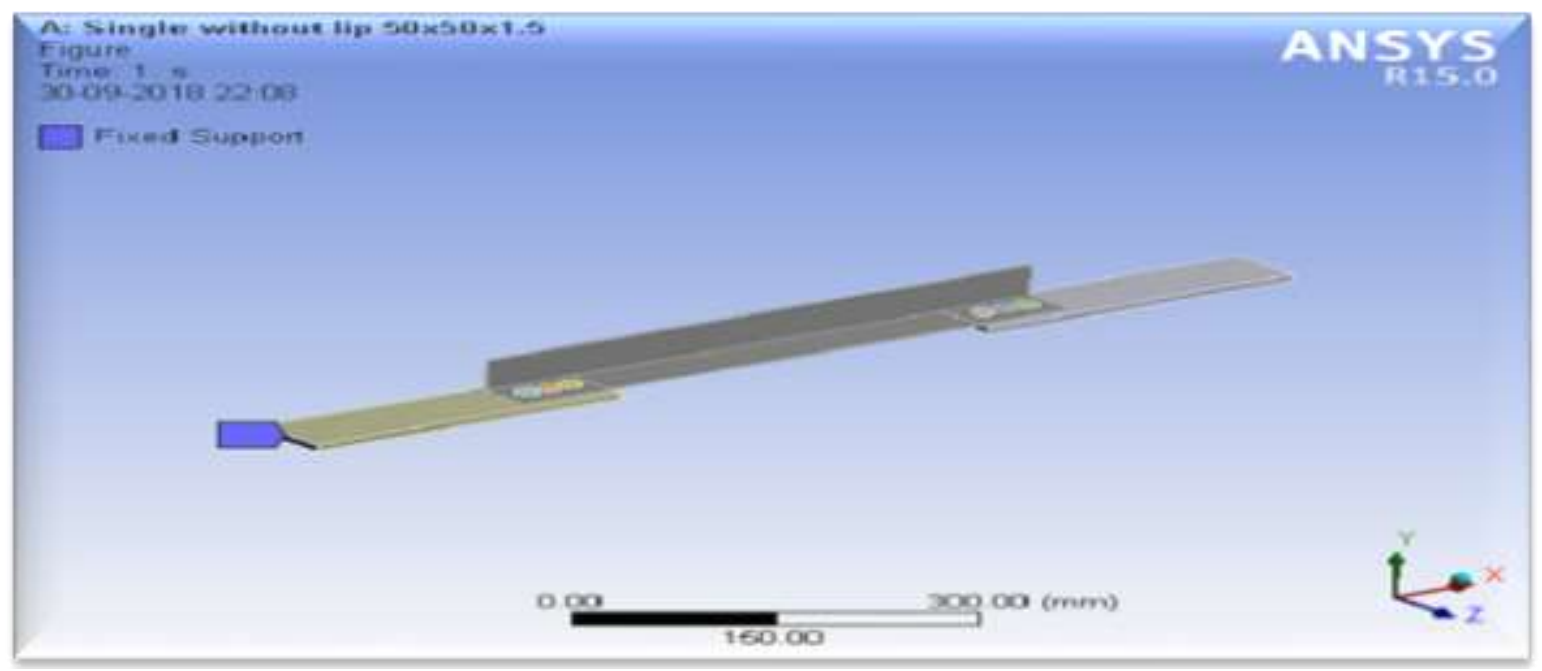

Fig 11aFixed Support conditions of single angle specimens without lip 50x50x2

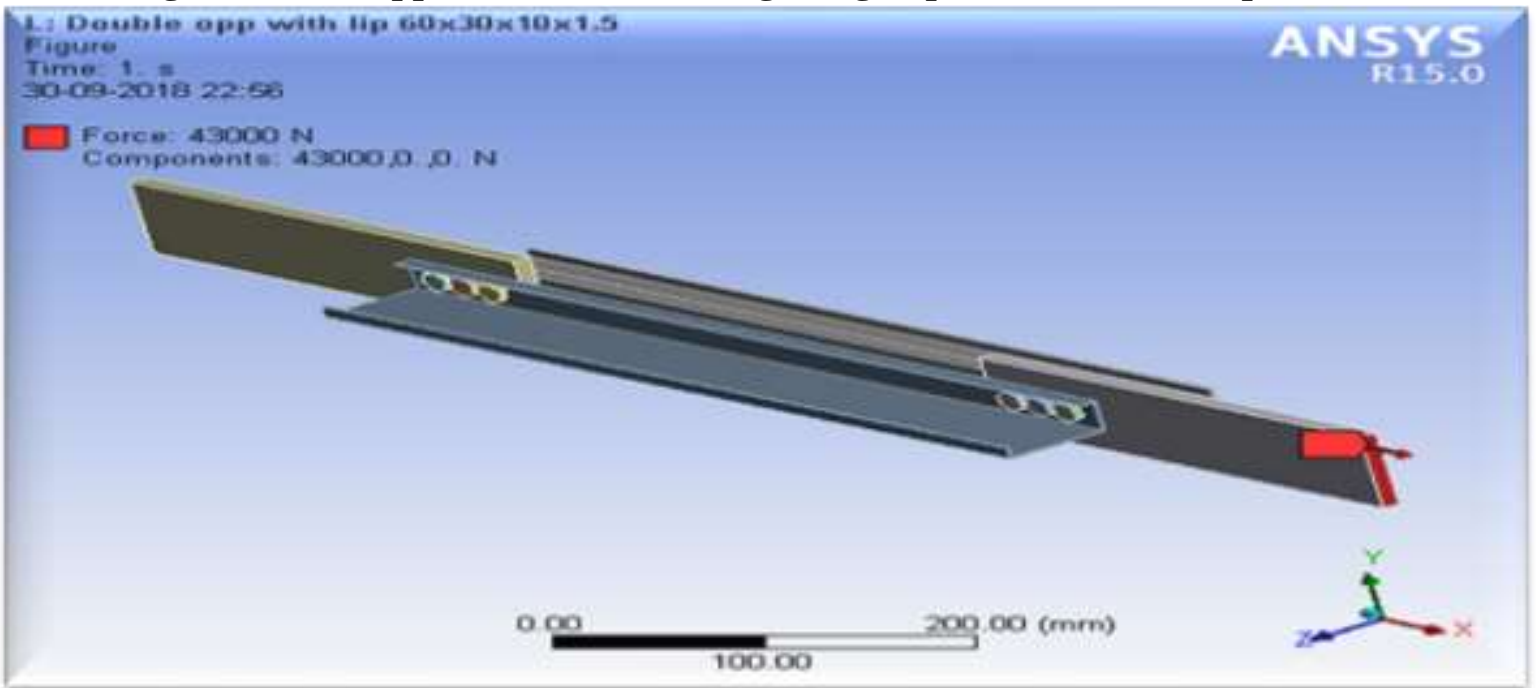

Fig 11b Loading conditions of double angle connected to opposite side with lip $60 \times 30 \times 10 \times 3$ 


\section{RESULTS}

\subsection{Results of stress and strain distribution, total deformation from ANSYS 15.0}

The stress distribution, strain distribution, and total deformation for cold formed steel angle sections are presented in Appendix B2.1 to B2.15. The effect of stress was observed more in the outstanding leg and therefore the outstanding leg experiences local buckling. It is observed that the lip experiences local buckling and the stress concentration is more nearer to the bolt holes as expected. For lipped angles, it was seen that the separation of angles take place in the connected portion. In addition, plate curling was observed in the unconnected leg. Similarly stress vs strain graphs shows linear proportionally upto $420 \mathrm{~N} / \mathrm{mm}^{2}$ stress, then slope of the line changes as section changes elastic state to elastic plastic state. Double lipped unequal angle connected to same side (70x35x10x3), the maximum stress value obtained are $423.02 \mathrm{~N} / \mathrm{mm}^{2}$ and for strain value 0.0028482 . The maximum deflections are $10.24 \mathrm{~mm}$ with buckling load $214.29 \mathrm{KN}$. The maximum stress is observed near fix end support within the effective length of the angle section, uniform stress distribution is shown in green color, which causes bending of the section. Therefore, the failure pattern is observed of angle sections are bending failure. The maximum stress value obtained from ANSYS is $424.23 \mathrm{~N} / \mathrm{mm}^{2}$. It shows much lesser value of stresses developed at the edges of the section. It was observed that failures of angle section are irregular, it shows convex and concave failure pattern and it fails near the support.

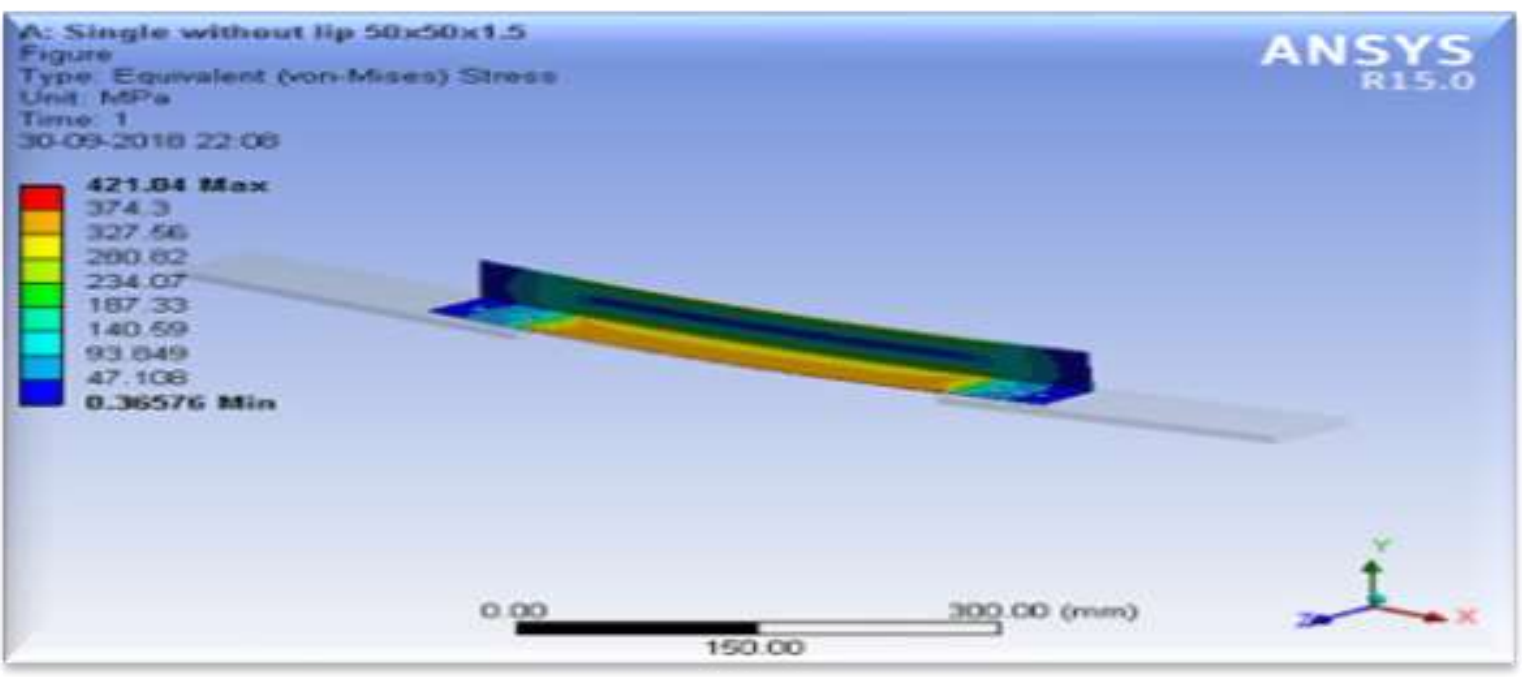

Fig 12a Stress distribution for single plane angle without lip 50x50x1.5

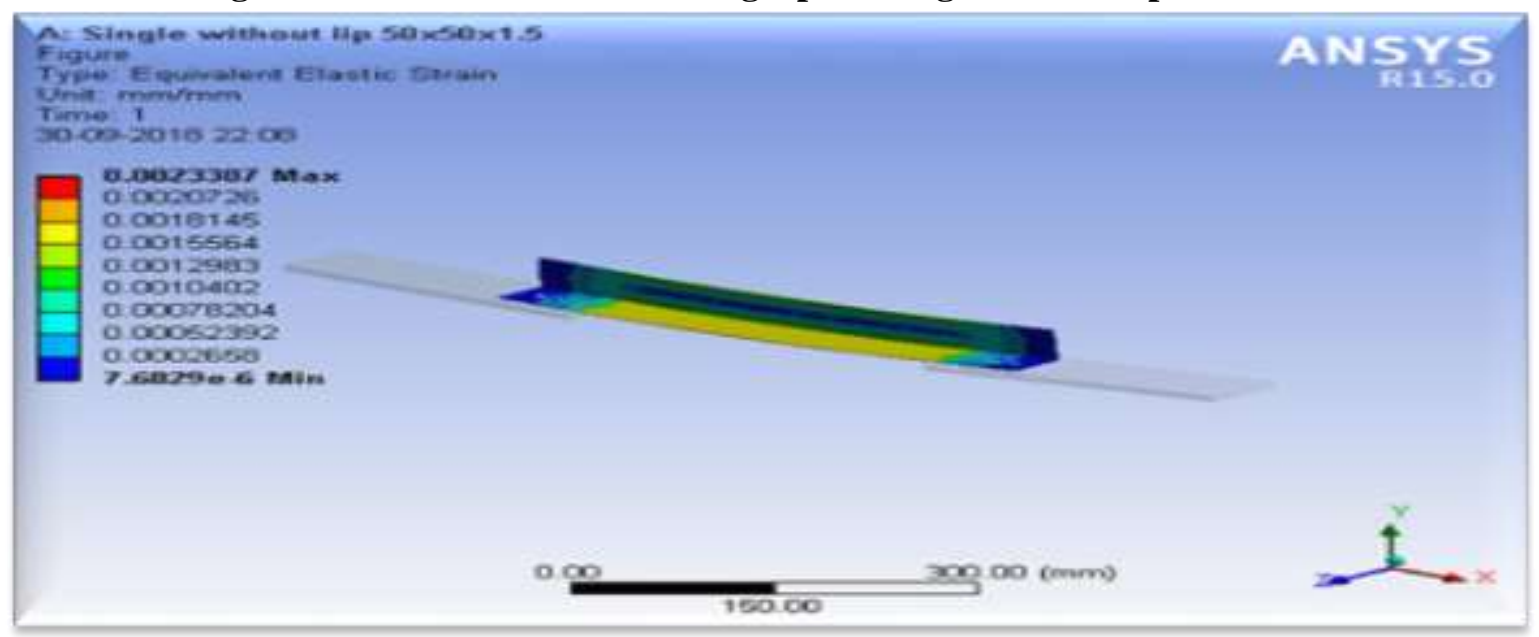

Fig 12b Strain distribution for single plane angle without lip 50x50x1.6 


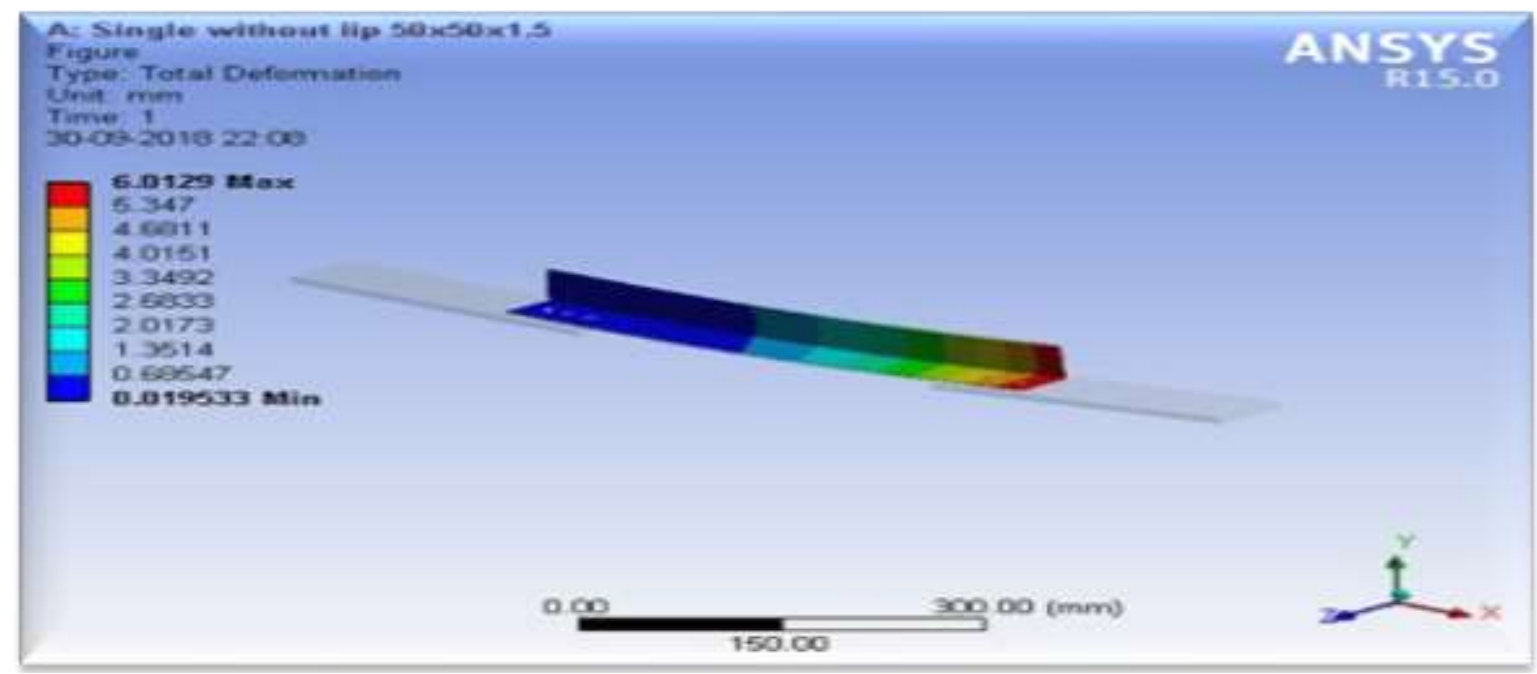

Fig 12c Total deformation for single plane angle without lip 50x50x2

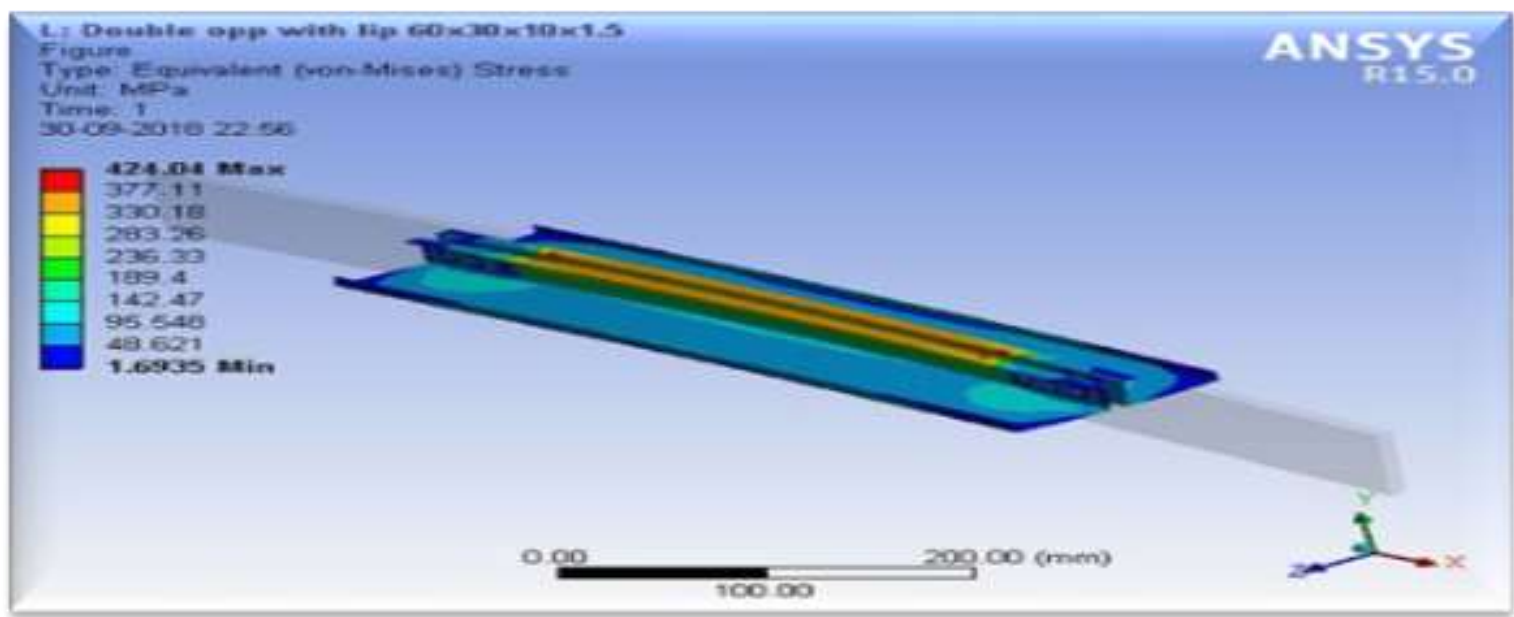

Fig 12d Stress distribution for double angle connected to opposite side with lip 60x30x10x3

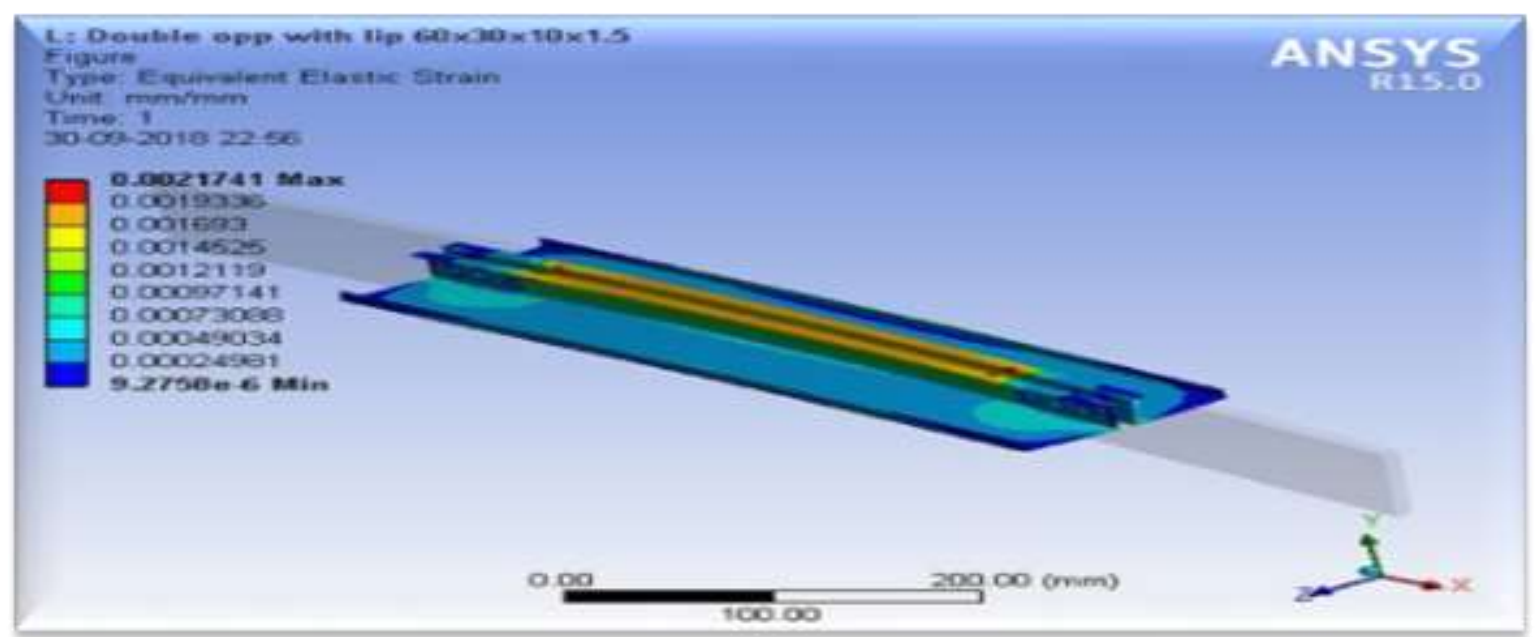

Fig 12e Strain distribution for double angle connected to opposite side with lip 60x30x10x4 


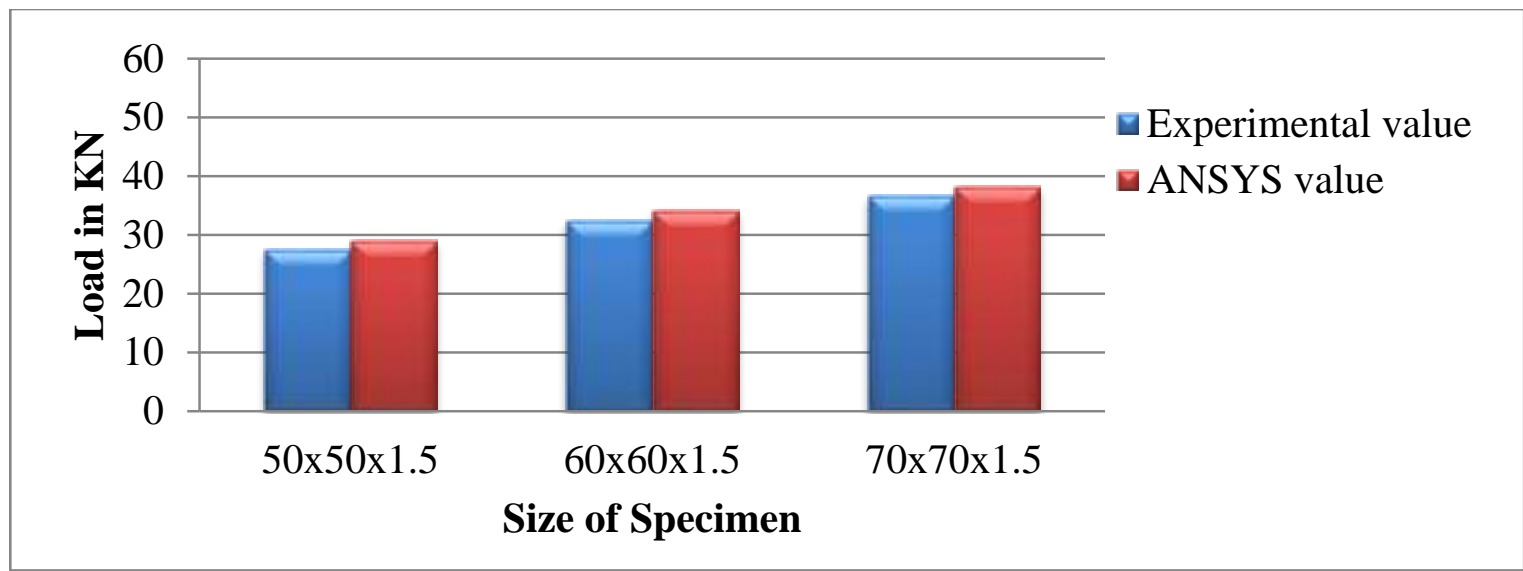

Fig 13a Comparison of experimental and Ansys load for single equal angle specimens (1.5mm)

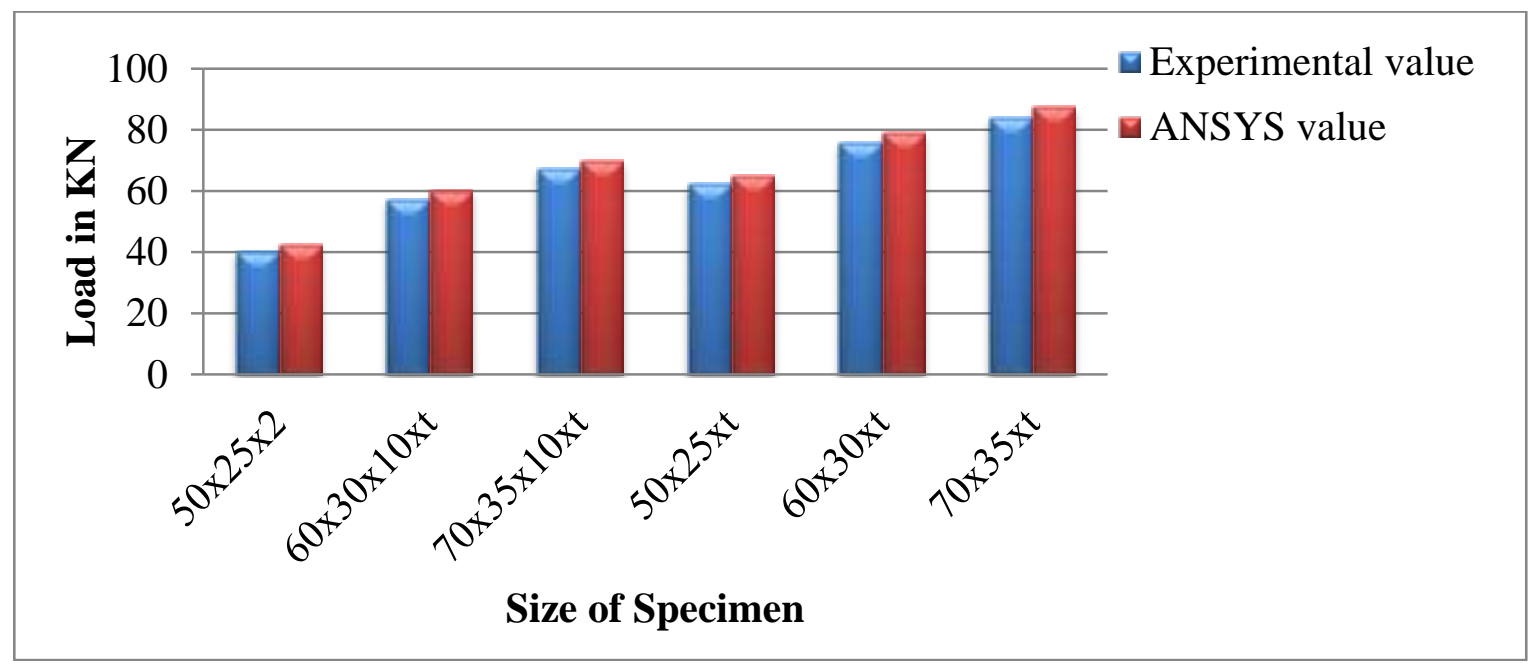

Fig 13b Comparison of experimental and Ansys load double angle specimen connected to same side $(3 \mathrm{~mm})$

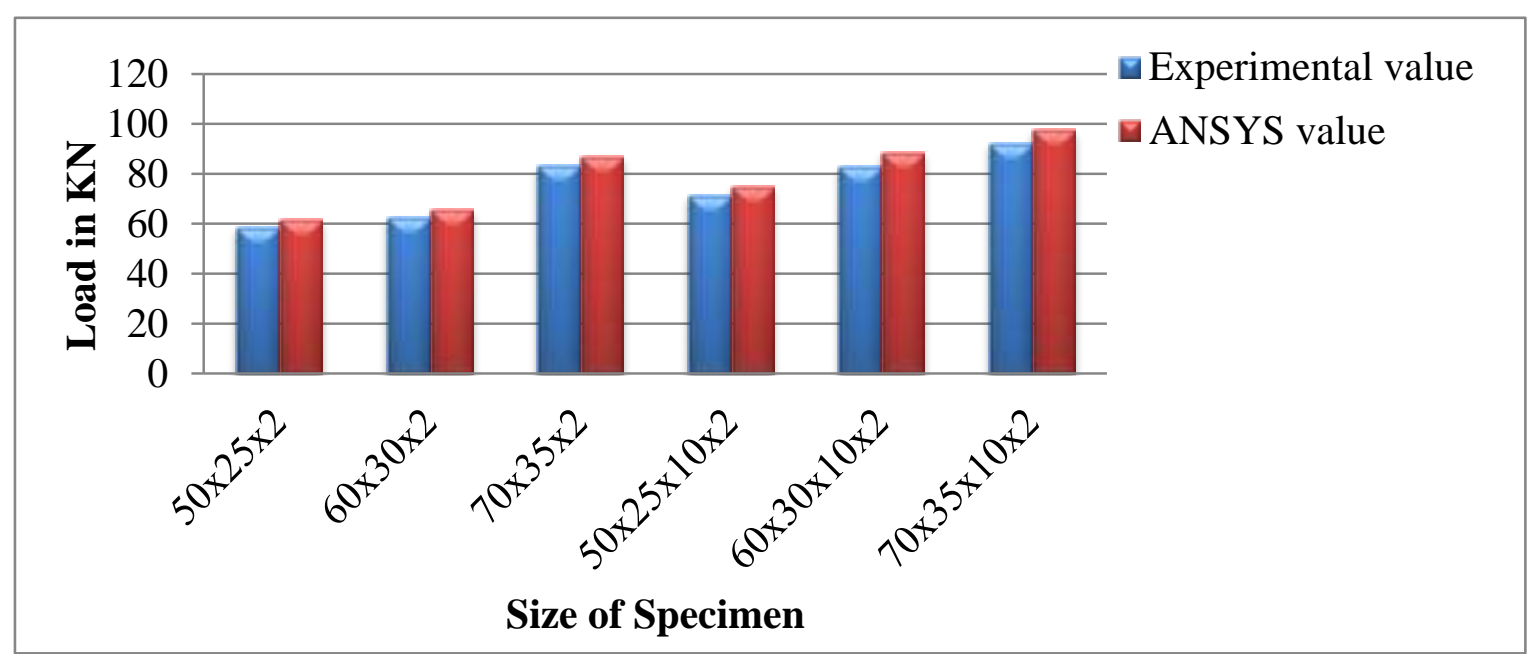

Fig 13c Comparison of experimental and Ansys load for double unequal angles specimen connected to same side $(2 \mathrm{~mm})$ 


\section{CONCLUSION}

The ultimate load carrying capacity increases as the cross - sectional area increases. Provision of more number of bolts improves the connection rigidity, which also contributes to increase in load carrying capacity and the $8 \mathrm{~mm}$ gusset plates thickness reached nearly the yield stress where the maximum capacity of the connection is reached.The cold formed steel angle sections experimental load versus deflection curves showed that the ultimate load carrying capacity increases with the cross- sectional area and the number of bolts in the connection. It is observed that the stiffness of the connection increases with the stiffness of the member.

The finite element modeling using ANSYS software closely predicts the ultimate strength and behaviour of cold formed steel angles. Hence, the finite element analysis can be used for parametric studies. The ultimate strength is the maximum stress that a material can withstand before it breaks. It is observed from the graphs that the top load of test valves is similar to numerical valves for specimens. The stress contour in the finite element analysis indicates the maximum stress occur in the innermost bolt holes from which the experimental failure were intimated.Economy are achieved by using the cold formed steel angle sections wherever possible in hot rolled steel structures. The advantages of cold formed steel lie in the ease of forming the variety of shapes designed to use the material effectively and to simplify and the speed up the construction operation.

\section{REFERENCES}

[1] Ben Young 2005, 'Experimental Investigation of Cold-Formed Steel Lipped Angle Concentrically Loaded Compression Members', Journal of Structural Engineering, vol. 131, no. 9, pp. 1390-1396

[2] Ben Young \& Ehab Ellobody 2006, 'Buckling Analysis of Cold-Formed Steel Lipped Angle Columns', Journal of Structural Engineering, vol. 131, no. 10, pp. 1570-1576

[3] Bhavitha, E \& Rosemol, $K$ 2015, 'Comparative study on moment connections in cold formed steel sections with and without perforations', International journal of Innovative science, Engineering \& Technology, vol. 2, no. 11, pp. 478-481

[4] Cam Tokay 2004, 'A finite element parametric study on block shear failure of steel tension members', Journal of Constructional Steel Research, vol. 60, no. 11, pp. 1615-1635

[5] Chakherlou \& Oskouei 2008, 'Experimental and numerical investigation of the effect of clamping force on the fatigue behaviour of bolted plates', Engineering Failure Analysis, vol. 10, no. 5, pp. 563-574

[6] Cher Siang Tan \& Mahmood, MD 2015, 'Experimental Investigation of Bolted Angle Joints for Cold-formed Steel Double Channel Sections', International Journalof structural analysis and Design, vol. 2, no. 2, pp. 14-17

[7] Chou, SM \& Chai, GB 2000, 'Finite Element Technique for Design of stub Columns', ThinWalled Structures, vol. 37, no. 2, pp. 97-112

[8] Chung, KR \& Ip, KH 2000, 'Finite Element Modeling of Bolted Connections between cold formed steel strips and hot rolled steel plates under static shear loading', Engineering Structures, vol. 4, no. 22, pp. 1271-1284

[9] Chung, KF \& Lau, L 1999, 'Experimental Investigation on bolted moment connections among cold formed steel members', Engineering Structures, vol. 2, no. 21, pp. 898-911 
[10] Davi Fagundes Leal 2017, 'Numerical analysis of cold-formed double angles back-to-back under compression', REM International Engineering Journal, $\quad$ vol. 70, no. 4, pp. 399-406

[11] Deepla, $N$ \& Venkat, $R$ 2018, 'Comparitive Study on Cold Formed Light Gauge Steel Angle Sections and Channel Sections of Compression Members', Journal of Applied Science and Innovations, vol. 2, no. 1, pp. 7-14

[12] Dubina \& Ungureanu 2002, 'Effect of imperfections on numerical simulation of instability behaviour of cold-formed steel members', Thin-Walled Structures, vol. 40, no. 3, pp. 239-262

[14] Fadhluhartini Muftah \& Mohd Syahrul 2014, 'Ultimate load of built-up cold formed steel column', Journal of Engineering and Applied Sciences, vol. 9, no. 11, pp. 2095-2101

[15] Gotluru 2000, 'Behavior of cold formed steel beams having open sections which were subjected to torsion', Journal of Engineering structures, vol. 2, no. 3, pp. 1374-1975

[16]Gregory Hancock, J 2016, 'Cold-formed steel structures: Research review 2013-2014', Advances in Structural Engineering, vol. 19, no. 3, pp. 1-16

[17]Guangfan, LI \& Yong Huang 2011, 'Experimental Investigation on Slip-In Connection for Cold-Formed Steel Double Channel Sections', Advanced Materials Research, vol. 25, no. 5, pp. 1038-1041

[18]Salokhe, S \& Patil, P 2015, 'Comparative study of behaviour of cold formed steel and hot rolled steel section under compressive loading', International Journal of Research in Engineering and Technology, vol. 4, no. 4, pp. 517-522

[19]Schifferaw \& Schafer 2007, 'Inelastic bending capacity in cold formed steel members', Construction research of steel structures, vol. 6, no. 5, pp. 571-553

[20]Soheila Maduliat \& Priyan Mendis 2014, 'Post-yield capacity of cold-formed channel sections in bending', Structures \& Buildings, vol. 167, no. 8, pp. 1-12

[21]Sonal Banchhor \& Gupta, MK 2016, 'Experimental investigation of bolted cold formed steel angle Under tension', International Journal of Engineering Sciences \& Research Technology, vol. 5, no. 7, pp. 210-220 